\title{
Os paradoxos da existência e a psicoterapia: Rollo May e Kierkegaard
}

The paradoxes of existence and psychotherapy: Rollo May and Kierkegaard

\section{Las paradojas de la existencia y la psicoterapia: Rollo May y Kierkegaard}

Carlos Campelo da Silva ${ }^{1}$

\footnotetext{
${ }^{1}$ Mestre em Ciências da Religião pela Pontifícia Universidade Católica de Campinas (PUCCampinas). Graduação em Psicologia - Universidade Paulista (UNIP). Docente do curso de Psicologia da Universidade Metodista de Piracicaba (UNIMEP). Coordenador do curso de Psicologia - Universidade Metodista de Piracicaba. (UNIMEP)

E-mail: carloscampelo.psi@gmail.com

Trabalho apresentado no IV Congresso Luso-Brasileiro de Práticas Clínicas Fenomenológico existenciais.
} 


\title{
Resumo
}

O objetivo deste trabalho é apresentar o conceito do paradoxo na clínica existencialhumanista, a partir de Rollo May e Kierkegaard. Ao utilizar a palavra dilema no título de seu livro A psicologia e o dilema humano (1979), Rollo May (1909-1994), explica que não a utiliza em um sentido técnico, mas seu uso consiste em referir-se às polaridades e aos paradoxos que são inescapavelmente humanos. Entretanto, ainda que o paradoxo seja parte fundamental da existência humana, muitas vezes tentamos fugir dele desenvolvendo excessivamente uma das polaridades para escapar da outra. Daí surgirem muitos distúrbios que conduzem as pessoas às clínicas e aos consultórios psicoterapêuticos. Porém, o psicólogo norte-americano salienta que as polaridades são também a fonte de energia e de criatividade humana, pois é do confronto construtivo das tensões, que o paradoxo produz, que nos tornamos criativos. O conceito de paradoxo é fundamental no pensamento do filósofo dinamarquês Søren Kierkegaard (1813-1855), de quem Rollo May recebe influência e, desse modo, o presente artigo pretende afirmar a importância do paradoxo na existência humana e na clínica existencial-humanista.

Palavras-chave: Psicoterapia; Dilema humano; Paradoxo; May; Kierkegaard.

\begin{abstract}
The objective of this work is to present the concept of the paradox in the existentialhumanist clinic, from Rollo May and Kierkegaard. When using the word dilemma in the title of his book Psychology and the human dilemma (1979), Rollo May (1909-1994) explains that he does not use it in a technical sense, but its use consists in referring to polarities and paradoxes who are inescapably human. However, even though the paradox is a fundamental part of human existence, we often try to escape from it by excessively developing one of the polarities to escape the other. Hence, many disorders arise that lead people to psychotherapeutic clinics and offices. However, the North American psychologist points out that polarities are also the source of human energy and creativity, as it is from the constructive confrontation of the tensions that the paradox produces that we become creative. The concept of paradox is fundamental in the thinking of the Danish philosopher Søren Kierkegaard (1813-1855), from whom Rollo May is influenced, in this way, this article intends to affirm the importance of the paradox in human existence and in the existential-humanist clinic.
\end{abstract}

Keywords: Psychotherapy; Human dilemma; Paradox; May; Kierkegaard. 


\section{Resumen}

El objetivo de este trabajo es presentar el concepto de paradoja en la clínica existencialhumanista, de Rollo May y Kierkegaard. Al usar la palabra dilema en el título de su libro Psicología y el dilema humano (1979), Rollo May (1909-1994), explica que no la usa en un sentido técnico, sino que su uso consiste en referirse a polaridades y paradojas que son ineludiblemente humanas. Sin embargo, aunque la paradoja es una parte fundamental de la existencia humana, a menudo intentamos escapar de ella desarrollando excesivamente una de las polaridades para escapar de la otra. De ahí que surjan muchos trastornos que llevan a las personas a clínicas y consultorios psicoterapéuticos. Sin embargo, lo psicólogo norteamericano señala que las polaridades son también fuente de energía y creatividad humana, ya que es a partir del enfrentamiento constructivo de las tensiones, que produce la paradoja, que nos volvemos creativos. El concepto de paradoja es fundamental en el pensamiento del filósofo danés Søren Kierkegaard (1813-1855), de quien se influye Rollo May, de esta forma, este artículo pretende afirmar la importancia de la paradoja en la existencia humana y en la clínica existencial-humanista.

Palabras clave: Psicoterapia; Dilema humano; Paradoja; May; Kierkegaard. 
"Todas as pessoas trazem em si o espírito de contradição e o prazer pelo paradoxo"

(Goethe, Poesia e Verdade, p. 421)

\section{Introdução}

Em 1969, no prefácio da segunda edição da obra Psicologia Existencial, Rollo May (1909-1994) cunha o termo "psicologia existencial-humanista". Essa perspectiva de psicologia permanece viva, contando com nomes como Irvin Yalom (1931) e Kirk Schneider (1956). A psicologia existencial, tal como foi concebida por May, distingue-se de outros modelos de terapia existencial, haja vista as várias influências que o psicólogo norte-americano recebeu e não abriu mão de utilizá-las na compreensão do ser humano.

May foi influenciado pelo pai da psicanálise Sigmund Freud, mas principalmente pelos neo-freudianos Erick Fromm, Harry Stack Sullivan e Otto Rank. Além disso, também recebeu influência da Psicologia Analítica de Carl Jung e da Psicologia Individual de Alfred Adler. E não para por aí, já que May inspirou-se ainda no trabalho de Willian James. Nesse contexto, de todas essas referências, uma das mais importantes para o desenvolvimento de sua psicologia existencial foi o contato que teve com o filósofo e teólogo Paul Tillich. Ele conheceu Tillich ainda em 1933 enquanto estudava teologia no Union Theological Seminary. Tillich foi o responsável por apresentar o filósofo Søren Kierkegaard a May, e é principalmente essa referência que queremos analisar daqui em diante, em especial, o uso do conceito do paradoxo por May, sendo esse conceito uma categoria fundamental do pensamento de Kierkegaard.

Muito antes de publicar o livro Existence: a new dimension em Psyquiatry e and Psychology, em 1959, que tornaria May conhecido como um psicólogo existencialista (May, 2012, p. 13), o pensador dinamarquês já era uma referência importante em seu pensamento. Dez anos antes, ele defenderia a sua tese sobre $O$ significado da ansiedade, que seria publicada como livro no ano seguinte. Nessa obra, Kierkegaard surge como uma referência fundamental para a compreensão do tema da ansiedade que May estudava naquele momento, porém, mais do que uma referência para sua tese, a experiência de May com Kierkegaard foi a nível existencial. É o próprio May quem nos conta:

Há alguns anos atrás, enquanto trabalhava em meu livro $O$ significado da ansiedade, contraí tuberculose e passei um ano e meio no leito, em um sanatório. Naquele tempo, não havia remédios para a doença; e, enquanto esperava, hora após hora, e dia após dia, até o final de cada mês, para ver se o raio-X mostraria minha cavidade pulmonar tornando-se menor ou maior, tive tempo bastante para ponderar o significado da ansiedade - e suficientes dados de primeira mão em mim próprio e em meus 
companheiros enfermos. No decurso da doença, estudei os dois únicos livros escritos até aquele momento sobre a ansiedade: $O$ problema da ansiedade, de Freud, e $O$ conceito de angústia de Kierkegaard. [...] O que me impressionou fortemente foi que Kierkegaard escrevia precisamente sobre o que meus companheiros doentes e eu próprio estávamos sofrendo. (May, 1961/1986, p. 3)

Desde então, May, não deixou de amparar-se em Kierkegaard e em sua Psicologia Existencial, e essa característica experiencial, tal como descrita no fragmento acima, é o que une tantos autores diversos no pensamento de May: "O que importa no pensamento existencialista de May é o ser da experiência imediata, ou seja, o que é vivido como sentido. May procura compreender todos os autores que explora nesta direção interpretativa". (Barrocas citado por Ponte \& Sousa, 2011, p. 52).

\section{O dilema humano: a importância do paradoxo na psicoterapia}

Em 1990, Rollo May fez uma nota introdutória ao livro do seu discípulo Kirk Schneider, que estampava em sua capa o título de Self Paradoxical. Nessa nota, May afirma: "trata-se do paradoxo da vida sobre o qual falam Paul Tillich, Kierkegaard, Nietzsche e outros, mas que foi esquecido na nossa época de pseudoprosperidade" (1993, p. 9). Desse modo, May conclui que Schneider está bem acompanhado em suas reflexões. E por que não acrescentar a essa companhia o nome do próprio Rollo May?

Ao falar da importância do conceito de paradoxo para a psicologia em 1990, May apenas reafirma o que havia afirmado expressamente em 1967 em sua obra A psicologia e o dilema humano. Embora seja a palavra "dilema", e não "paradoxo", que está na capa do livro, May explica que esse termo não é utilizado em seu sentido técnico, e sim usado em referência às polaridades e aos paradoxos da existência humana. Desse modo, ao esclarecer o tema da obra, Rollo May, salienta que:

Ele origina-se da grande variedade e riqueza da natureza humana, de um lado, e da banalidade e mesquinharia, de outro. Esse tema origina-se também do contraste entre a generosidade do ser humano e a suprema crueldade de que somos igualmente capazes. Apresentamos uma capacidade admirável para a razão, mas ela está em perpétuo conflito com o nosso comportamento espantosamente irracional. Nós temos a experiência da alegria e da criatividade num dia e, no dia seguinte, observamos que não diminuímos em nada a nossa propensão para o desespero e a frustração (May, 1967/2009, p. 9).

Desse modo, fica claro que é sobre o paradoxo que May quer tratar. Para o autor, são esses paradoxos que levam as pessoas aos consultórios psicológicos, pois ao tentar escapar do 
paradoxo, muitos acabam desenvolvendo excessivamente um lado da polaridade e, assim, surgem muitos distúrbios (May, 1967/2009, p. 10). Alguns tentam escapar do paradoxo, tentando enfatizar apenas o lado objetivo da vida, enquanto outros, tentam enfatizar o lado subjetivo. Para May, isso é uma super simplificação².

Nesse sentido, May observa que a psicoterapia de sua época estava efetuando uma super simplificação do ser humano ao não considerar o paradoxo. Para ilustrar tal cenário, o psicólogo recorre à controvérsia Rogers-Skinner ${ }^{3}$. De acordo com May (1967/2009, p. 34), Skinner, a partir do seu trabalho sobre condicionamento operante, acredita que o paradoxo pode ser evitado por meio da aplicação "universal dos seus pressupostos e métodos comportamentais". Skinner (citado por May, 1967/2009, p. 34) argumenta que “o organismo individual simplesmente reage de preferência ao seu ambiente, do que a alguma experiência interna daquele ambiente, a bifurcação da natureza em propriedade físicas e psíquicas pode ser evitada".

Do outro lado da questão, temos Carl Rogers (1902-1987), o qual argumentava firmemente que é o controle interior que é significante, pois “é centrado no cliente" e não no ambiente:

Rogers sempre acreditou que se você dá ao paciente o relacionamento humano certo ou seja, aquele marcado pela "congruência", respeito, aceitação de todos os sentimentos - então o paciente crescerá de modo totalmente natural na direção da maturidade, da responsabilidade e de outros objetivos terapêuticos comumente aceitos. Rogers foi descrito como rousseauniano e prontamente aceitou a classificação. De maneiras diferentes, ele afirma e reafirma a sua crença de que o ser humano é "requintadamente racional", e escolherá o que é racionalmente melhor para ele, se lhe for dada a oportunidade correta. Tudo isso resulta numa afirmação enfática do outro lado do dilema. (May, 1967/2009, p. 37)

Para May, escolher apenas um polo, o objetivo ou o subjetivo, o ambiente ou a capacidade interior, a fim de evitar o paradoxo, é efetuar uma super simplificação do ser humano. De acordo com o autor, ambos são necessários. "Necessários para a ciência psicológica, para uma terapia efetiva, e para uma vida cheia de sentido", uma vez que é no

\footnotetext{
${ }^{2}$ May utiliza o vocabulário latino nimis simplificandum. A edição em português, em nota de rodapé, explica que: Nimis significa "excessivo", e simplificandum, "simplificante". Poderíamos, assim, traduzir para o vernáculo moderno como "supersimplificante" (Cf. May, 2009, p. 19).

${ }^{3}$ A controvérsia Rogers-Skinner, ocorreu no ano de 1956, e à época foi uma das publicações mais reimpressas no mundo da psicologia (Cf. Rogers, 1974/1977, p. 35).
} 
processo dialético entre esses dois polos que "reside o desenvolvimento, o aprofundamento e a ampliação da consciência humana". (May, 1967/2009, p. 41).

\section{Kierkegaard: o pensador do paradoxo}

Enquanto May percebe na psicologia de sua época um conflito entre objetividade e subjetividade, que acabava por perder o ser humano em sua completude, observa também que o filósofo dinamarquês Søren Kierkegaard (1813-1855), muitas vezes acusado injustamente de subjetivista, "abre os portões do mundo subjetivo sem perder a objetividade" (May, 1983/1993, p. 77). Desse modo, May, inicia o primeiro capítulo de sua obra com uma citação de Kierkegaard acerca do paradoxo: "Porém, não há que pensar mal do paradoxo; porque o paradoxo é a paixão do pensamento, e o pensador sem paradoxo é como o amante sem paixão: um tipo medíocre" (Kierkegaard, 1844/2012, p. 84).

O tema do paradoxo e o tema correlato do absurdo são constantes na obra de Kierkegaard ${ }^{4}$. O paradoxal é sua arma para enfrentar o racionalismo de sua época, no qual tudo se dissolvia em sistemas absolutos e mediações lógicas. Kierkegaard quer mostrar a esses racionalistas que eles estavam presos em um raciocínio circular, uma vez que: "qualquer compreensão coerente baseia-se e deve basear-se sobre algo que não pode por si só ser expressado nos termos desse sistema" (McKinnon citado por Gouvêa, 2006, p. 191). É por isso que Climacus/Kierkegaard (1844/2012, p. 84) irá afirmar que

[...] a superior potência de qualquer paixão é querer sempre a sua própria ruína, e assim também a superior paixão do entendimento é querer a colisão, se bem que a colisão tenha de ser, de um modo ou de outro, a sua ruína. Este é, pois, o paradoxo do pensamento: querer descobrir algo que ele próprio não é capaz de pensar.

Somente, quando o pensamento entra em colisão, isto é, encontra o seu limite, é possível avançar, uma vez que uma proposição paradoxal irá forçar-nos a uma redefinição do conceito e "quanto mais redefinições conceituais ela pede, mais paradoxal é a afirmação". Desse modo, Gouvêa conclui "que o paradoxo é o verdadeiro motor do pensamento" (2006, p. 174). Entretanto, o autor também alerta que há um perigo aqui, "o perigo é que se chegue a acreditar que todo e qualquer paradoxo pode e deve ser resolvido ou "guardado" numa conceituação mais elevada e não paradoxal” (2006, p. 174):

\footnotetext{
${ }^{4}$ O termo "paradoxo" aparece 131 vezes no Samlede Vaerker (obras reunidas de Kierkegaard (Cf. Gouvêa, 2006, p. 181).
} 
Contudo, o paradoxo não pode ser anulado. Eventualmente chega-se ao ponto onde, humanamente falando, o paradoxo não pode ser mais explicado. A menos que acreditemos que, em algum sentido somos divinos, temos de admitir que o paradoxo vencerá por fim, pois ele é aquilo que a compreensão não pode compreender; e a compreensão humana tem que ter um limite, pelo menos se continua a ser meramente humana. (Gouvêa, 2006, p. 174)

Por isso, Climacus, no Pós-escrito (1846) irá defender que para um ser humano existente é impossível um sistema completo, um sistema assim só serviria para Deus ${ }^{5}$. Quanto aos homens, esses têm que viver com a angústia do paradoxo. "Se um humano fosse um animal ou um anjo, não poderia angustiar-se. Dado que ele é uma síntese, pode angustiar-se, e quanto mais profundamente se angustia, tanto maior é o ser humano" (Haufinienses/Kierkegaard, 1844/2010, p. 163).

Desse modo, fica claro que o paradoxo, mas do que somente uma categoria do pensamento, ele é inerente à existência humana. A concepção do ser humano constituído como polaridades em tensão é apresentada tanto em $O$ conceito de angústia (1844), quanto na obra $A$ doença mortal (1849). Na primeira, Kierkegaard apresenta as polaridades do psíquico e do corpóreo (Kierkegaard, 1844/2010, p. 47), enquanto na segunda apresenta as polaridades do finito e do infinito (Kierkegaard, 1849/2010, p. 25).

Essa compreensão ampla do ser humano aponta para o fato de que não é possível compreender um ser humano apenas observando aspectos objetivos e tampouco somente subjetivos, como tem sido feito por muitas teorias psicológicas, uma vez que o ser humano é uma síntese.

\section{Considerações finais}

Søren Kierkegaard (1813-1855) e Rollo May (1909-1994) compreenderam a importância do paradoxo para a existência humana. Kierkegaard fez uso do paradoxo contra a filosofia e a teologia racionalista de seu tempo, a fim de mostrar os limites do pensamento sistemático, que pretendia dissolver a existência humana em conceitos. Enquanto May combateu o racionalismo na psicologia de sua época que se dividia em objetivismo e

\footnotetext{
${ }^{5}$ Um sistema da existência não pode haver. Então não existe um tal sistema? De modo algum! Isso está implicado no que foi dito. A existência mesma é um sistema - para Deus, mas não pode sê-lo para algum espírito existente. Sistema e completude se correspondem mutuamente, mas existência é justamente o contrário. (Kierkegaard, 1846/2013, p. 124).
} 
subjetivismo e, de acordo com o autor, o erro de ambos os lados é acreditar que se pode evitar o paradoxo, adotando um de seus polos.

Tanto para Kierkegaard, quanto para May, a evitação do paradoxo, seja pelo caminho da objetividade seja pela via da subjetividade, faz com que o ser humano viva uma vida aquém das suas capacidades. Porém, muitas vezes nos angustiamos frente ao paradoxo e, de acordo com Gouvêa (2006, p. 172), ele pode também ser irritante. Entretanto, conforme aprendemos com Kierkegaard (1844/2012, p. 84) "o paradoxo é a paixão do pensamento". O paradoxo nos desafia e nos faz crescer, desse modo, podemos afirmar, juntamente com May, que o paradoxo pode contribuir muito para "a ciência da psicologia, para a terapia e para uma vida gratificante" (May, 1967/2009, p. 23). 


\section{Referências}

Goethe, Johann W. (2017). De minha vida: poesia e verdade. São Paulo: Unesp.

Gouvêa, Ricardo Quadros. (2006) Paixão pelo paradoxo. São Paulo: Fonte Editorial.

Kierkegaard, Søren. (2013). Pós-escrito às Migalhas filosóficas v. 1. Petrópolis, RJ, Vozes.

Kierkegaard, Søren. Migalhas filosóficas. (2012). Lisboa: Relógio D’Água.

Kierkegaard, Søren. O conceito de angústia. (2010) Petrópolis, RJ: Vozes; São Paulo, SP: São Francisco.

Kierkegaard, Søren. (2010). O desespero humano. São Paulo: Unesp.

May, Rollo. A psicologia e o dilema humano. (2009) Petrópolis, RJ, Vozes.

May, Rollo. A descoberta do ser. (1988). Rio de Janeiro: Rocco.

May, Rollo. Psicologia existencial. (1986). Rio de Janeiro: Globo.

Ponte, Carlos Roger Sales da, \& Sousa, Hudsson Lima de. (2011). Reflexões críticas acerca da psicologia existencial de Rollo May. Revista da Abordagem Gestáltica, 17(1), 47-58. Recuperado em 20 de julho de 2021, de http://pepsic.bvsalud.org/scielo.php?script=sci_arttext\&pid=S1809$68672011000100008 \& \operatorname{lng}=$ pt\&tlng=pt.

Rogers, Carl. A pessoa como centro. (1977) São Paulo: EPU.

Schneider, Kirk. O eu paradoxal. (1993). Petrópolis, RJ: Vozes. 